Article

\title{
Digital Transformation Supporting Transport Decarbonisation: Technological Developments in EU-Funded Research and Innovation
}

\author{
Anastasios Tsakalidis * (D), Konstantinos Gkoumas ${ }^{\mathbb{D}}$ and Ferenc Pekár \\ European Commission, Joint Research Centre (JRC), 21027 Ispra, Italy; \\ konstantinos.gkoumas@ec.europa.eu (K.G.); ferenc.pekar@ec.europa.eu (F.P.) \\ * Correspondence: anastasios.tsakalidis@ec.europa.eu; Tel.: +39-0332-78-5907
}

Received: 4 March 2020; Accepted: 4 May 2020; Published: 6 May 2020

check for updates

\begin{abstract}
The European Commission's Communication on a European Green Deal sets out the objective of achieving climate neutrality by 2050 , which will require a reduction in transport emissions. To this aim, digital technologies, together with connectivity and automation, are transforming traditional concepts of mobility, with a potential impact towards transport decarbonisation. New business models are emerging and giving rise to innovative mobility services including new online platforms for car-pooling, car or bicycle sharing services, freight operations, or smartphone applications offering real-time travel information and other analytics. This study provides an overview of the European Union (EU) funded research and innovation (R\&I) and related technologies that are influencing the uptake of digital transformation in transport and identifies issues and challenges from a European perspective. To that end, it follows a two-tier approach that examines policy and legislative initiatives from the European Commission, highlighting possible challenges and enablers. Moreover, it analyses transport technology developments in Europe, focusing on the technology maturity from EU R\&I framework programmes, using the European Commission's Transport Research and Innovation Monitoring and Information System (TRIMIS). The technology analysis provides insights that aid policy decisions related to funding allocation in future R\&I framework programmes.
\end{abstract}

Keywords: digital transformation; transport policy; knowledge management; transport research; transport innovation

\section{Introduction}

Transport is one of the main sectors of the European economy, also having a direct impact on the environment, safety and the overall quality of life. The European Commission's Communication on a European Green Deal sets out the objective of achieving climate neutrality by 2050, which will require a reduction in transport emissions [1]. To this end, more efforts are needed in order to support the deployment of innovative technologies related to the transport sector that will allow for transport emission reductions and induce systemic changes, helping the transition towards a sustainable transport system [2].

Targeted research and innovation (R\&I) facilitate regulatory policies and technological advancement towards addressing current socio-economic and environmental challenges in Europe. Transport systems include an extensive series of physical and organisational elements and are being characterised by an overall intrinsic complexity, interacting with different sectors. In this sense, the transport system can be considered as a complex, large-scale, interconnected, open, socio-technical (CLIOS) system [3], including elements from the built environment and the social-political domains. Furthermore, transport technology is more than technical hardware: while it may often comprise mostly 
technical elements, the organisational innovations and new mobility concepts which do not require hardware modifications can be also regarded as new technologies since they aim to use hardware in a different manner [4]. In the last decade, the technological applications across the transport systems and subsystems have been increasing in number and level of complexity, along with the overall technological development in neighbouring sectors (energy, information, and communication technology, etc.). A series of profound changes are visible in many aspects of society and all sectors of the economy, including transport, due to the extended uptake and integration of digital technologies, a notion generally referred to as digital transformation [5].

Nowadays, thanks to the digital transformation of the entire transport sector, new business models are emerging and give rise to innovative mobility services. New online platforms for freight operations, car-pooling, car or bicycle sharing services and smartphone applications offering real-time analytics and data on traffic conditions are some relevant examples changing transport. Meanwhile, transport activity in Europe is expected to continue to grow in the coming decades, with road transport preserving the dominant role among all transport modes [6]. Vehicles themselves are also being transformed by digital technologies. They are becoming increasingly smart as new on-board connected and cooperative services and increased levels of automation become available.

The advent of connected and automated transport (CAT) will likely provide a breaking point in mobility. Advances in the field of artificial intelligence (AI), on which autonomous vehicles heavily rely, are developing steadily at present and will likely bring extensive changes to mobility and transport systems, revolutionising all aspects of society and life. The impacts of such a revolution on transport can be far-reaching, from drastically reducing road accidents to allowing efficient traffic flows and decreasing road transport emissions. The introduction of connected and automated vehicles has the potential to support improve road safety, energy efficiency, urban accessibility, social inclusion and reduce congestion [6]. In the future, more transport applications will take advantage of dedicated digital platforms to better facilitate all available means of transport in an integrated manner, bringing together for instance autonomous, electric and sharing applications to offer mobility as a service (MaaS) [7]. However, policies should also consider and mitigate the potential negative implications of CAT, such as increasing road congestion due to the attractiveness of autonomous vehicles and a resulting shift from public transport to private vehicles. Policymakers must act to ensure that future transport is cleaner and more equitable than its car-centred present [8].

Along with the development of these technologies, a paradigm change in mobility use is already on the way. Traditional private car ownership is threatened by MaaS or transport as a service (TaaS), which represent a shift away from personally owned modes of transport towards on demand pay-per-use mobility solutions. Societal, economic and technological drivers are accelerating the disruptive impact of MaaS. Urbanisation, climate change, the sharing economy, big data or the need to better match demand and supply are some examples of MaaS enablers [9].

Digital technologies have also enabled fundamental reinvention service delivery. New forms of more sustainable freight delivery (e.g., bike-based delivery services) appear as viable alternatives to (last mile) delivery of goods, with the companies operating in freight transport and the logistics industry adopting both green practices and information systems [10]. Air-drones are also considered as a valid alternative in the future, with progress being made at the policy level too to set the right regulatory conditions for this technology, such as in the recent initiative of the European Commission's Directorate General for Mobility and Transport on drones, adopting rules on their operation [11]. Home delivery by air-drones is being promoted and supported by a growing number of firms, especially in rural environments, with many citizens in Europe potentially getting access to such services in the near future [12]; however, the potential safety and security impacts need to be addressed.

New technologies and digital transformations provide a series of opportunities for a positive transformation of the transport sector. Nevertheless, there are potential issues such as data collection, and related challenges such as privacy and cybersecurity that require attention. All the above have to be accompanied and addressed by an appropriate policy framework, integrated with R\&I actions 
underpinning this transition. In this context, in the European Union (EU), the European Commission adopted in 2017 the Strategic Transport Research and Innovation Agenda (STRIA) as part of the "Europe on the move" package [13], highlighting main transport R\&I areas and priorities for clean, connected and competitive mobility. STRIA identified priority areas with specific actions for future R\&I, outlined in seven roadmaps: (i) connected and automated transport, (ii) transport electrification, (iii) vehicle design and manufacturing, (iv) low-emission alternative energy for transport, (v) network and traffic management systems, (vi) smart mobility and services, and (vii) transport infrastructure.

The authors co-developed the Transport Research and Innovation Monitoring and Information System (TRIMIS) at the European Commission's Joint Research Centre (JRC) in order to provide an assessment of technology trends and R\&I capacities, to publish information and data, and to develop analytical tools on the European transport system [14]. One of the sub-tasks of TRIMIS is the creation of an inventory and the regular reporting on new transport technologies [15]. Under this task, TRIMIS supports the implementation of STRIA, tracks the status and developments in the field of transport, identifies innovative technologies and assesses their potential future impact by creating a transport R\&I database. A cornerstone of this process is the establishment of an assessment methodology based on the taxonomic clustering of transport technologies and the use of appropriate indicators [16]. This technology cluster can be integrated and enhanced with insights from other sources, for example intellectual property (IP) activity and scientific research activity (i.e., peer reviewed papers), in order to have a better picture of undertakings in the private sector and academia.

Considering the above, this study leverages the technologies that are influencing the uptake of digital transformation in transport and identifies issues and challenges from a European perspective. To that end, it follows a two-tier approach, that, (i) looks in depth into policy and legislative initiatives from the European Commission, highlighting possible challenges and enablers, and, (ii) analyses transport technology developments relevant to the digital transformation in Europe, focusing on the technology maturity from European research and innovation framework programs, using the methodology developed for TRIMIS [17].

The analyses focus on three STRIA roadmaps: smart mobility and services, cooperative, connected and automated transport, and network and traffic management systems, which have the most relevance and can be affected the most by the digital transformation in the transport sector. In fact, digital transformation has the potential of revolutionising smart mobility and services, it is a prerequisite for the greater development of cooperative, connected and automated transport and will enable a higher optimisation of network and traffic management systems.

Concerning smart mobility and services, there is a connection between new technologies, innovative transport services and the decarbonisation of the transport sector. Future mobility services will need to be part of smart and sustainable city strategies; incorporating an integrated transport system and the digital transformation of the transport sector can facilitate this transition.

Concerning cooperative, connected and automated transport, there is a need to test the readiness of CAT technologies across all modes, including the reliability and safety of automated road transport functions in complex traffic situations. The digital transformation will allow the further development of connected and automated transport operations.

Additionally, concerning network and traffic management systems, the transition to an advanced multi-modal transport system requires the optimisation of the entire transport network. The digital transformation can affect real-time demand through intelligent applications and user information services, while the enhancement of the automated nature of air traffic, building upon the broader uptake of technological innovation, is equally important.

\section{Policy and Legislative Initiatives at European Level}

The path to the digital transport era will not be quick and without pitfalls. Many technological, social and legislative barriers will need to be addressed. Standardisation issues for technologies that have not reached maturity and legal aspects (liability of automated vehicles, air-drones etc.) need to be 
addressed meticulously, in order to avoid future pitfalls, assist technology diffusion and achieve future safety and security goals. In this context, appropriate governance, regulatory, and public procurement strategies are fundamental, together with open, real-time data systems that allow for the validation and optimisation of integrated mobility eco-systems against overall targets [5]. The appropriate tools combined with the necessary data can indeed catalyse the transport system reform at all spatial levels.

In 2016, the EC started the Cooperative Intelligent Transport Systems (C-ITS) initiative to foster cooperative, connected, and automated mobility, which lead to the adoption of five principles for granting access to in-vehicle data and resources [18]. In May 2017, the Second Mobility Package introduced STRIA [13]. In May 2018, the European Commission revealed the Third Mobility Package with the objective of citizens benefitting from safer traffic, less polluting vehicles, and more advanced technological solutions while supporting the competitiveness of EU industry. Particular focus is given to autonomous mobility that has the potential to make transport safer, more accessible, inclusive, and sustainable, encompassing a strategy aiming to make Europe a world leader in fully automated and connected mobility systems. The successful implementation of such an ambition is strongly dependent on the accompanying legal framework, which includes data accessibility and protection, and on technological barriers and enablers [19]. In March 2019, the European Commission adopted new rules stepping up the deployment of C-ITS in the form of a delegated act, which is based on the ITS Directive. The specifications establish the minimal legal requirements for interoperability between the various cooperative systems used [20]. In July 2019, the Council of the European Union adopted a decision to object to the proposal for Delegated Regulation on C-ITS [21]. In September 2019, in the strategy "A Union that strives for more" presented to the European Parliament [22], the European Commission outlined six headline ambitions for Europe for the next five years and beyond including the ambition to make Europe fit for the digital age [23]. In January 2020, the European Commission adopted its 2020 Work Programme, confirming the ambitions and identifying challenges ahead [24].

Nevertheless, there are issues and activities that go beyond policy or where it is difficult to formulate appropriate policies. Technology acceptance is conditioned by human and economic factors, and is linked to current social issues (e.g., safety, security, sustainability, climate change), and society is often reluctant to accept new technologies, especially during a period of rapid technological advance or there is a risk of creating a digital divide between different categories of citizens. This deceleration phenomenon could be further intensified due to possible bottlenecks in the design and implementation phase of new technologies and services, also being directly and indirectly affected by multiple individual system factors (e.g., supply chain problems, policy decisions, maturity of regulations, and standards). The fragmentation of different technologies and standards in the transport domain (especially when they are used for the same applications) can also be an obstacle to efficient digital transformation of transport because it results in a lack of interoperability and may increase deployment costs.

\section{Methodology}

This section provides the methodology used to analyse the technological developments in EU-funded R\&I related to the digital transformation of transport. The analysis draws on the TRIMIS database, which collects information on publicly funded transport research and innovation projects across Europe [25]. In TRIMIS, projects funded by the European framework programmes (FPs) are retrieved through an automated data interchange, while projects funded by member states (MS) are inserted manually by national contact points. Due to these different approaches, the coverage of EU-funded projects is robust, while for national projects gaps may exist. Currently, the database contains over 6700 projects that started between 2000 and 2019.

Due to the gaps identified for MS projects, and because the most recent projects provide the best indication on technologies' state of play, in the current phase, only European 7th Framework Programme (FP7) and Horizon 2020 Framework Programme (H2020) projects between 2007 and April 2019 were included in the analysis. A total of 1946 projects fall within the scope, including 81 research-oriented projects from the Connecting Europe Facility (CEF) funding instrument. 
Within these projects, a total of 857 technologies were identified, categorised and assigned to 45 technology themes through a grounded theory approach [26-28].

In order to do so, a series of methodological steps was taken [29]:

1. The results of a study that identified technologies within European transport research projects $[30,31]$ were analysed by different researchers who have complementary experience in the field of transport innovation and individually assessed the technology list. Based on this review, a structured approach was consolidated and implemented on what constituted a distinct technology, aiming to align technology domains with those outlined in the STRIA roadmaps [32].

2. Out of the total number of project contained in the TRIMIS database, the projects falling under the two most recent framework programmes, FP7 and H2020, covering the timeframe from 2007 up to today, were analysed, focusing on the most recent advances in European R\&I. All 1946 project descriptions falling within this category were read and flagged when a technology was mentioned (EU-funded projects also cover non-technology-focused projects such as, for instance, those that encourage collaboration between different infrastructure managers). Once a technology was flagged in the project description, a second researcher validated the flagging and registered the technology name.

3. The full list of technologies was evaluated, and the labelling of similar technologies was aligned. The labels were inspired by existing taxonomies, such as those under the Cooperative Patent Classification [33].

4. A number of overarching technology themes were defined after the technology list was established. Themes enable a better understanding of how technologies cluster together and which fields of research receive relatively greater interest. An extensive list of themes was created and consequently reduced to the minimum number of themes under which all technologies could still be logically placed.

Following that, the technologies were assessed for their innovation potential on the basis of relevant criteria (total investment, number of projects that have researched the technology, number of organisations involved, technology development phase, etc.). The creation of the technology and technology theme taxonomy enables different visual representations. The next section provides some early analysis for technologies linked to the digital transformation of transport.

\section{Results}

The results of the analysis are presented in Figure 1, which provides an initial approach, focusing on the top seven technologies in terms of allocated budget for three STRIA roadmaps. Due to a lack of space, the figure is limited to the representation of only an intermediate branch, by collapsing lower nodes in the taxonomy (i.e., technology themes) and to three STRIA roadmaps: smart mobility and services (SMO), cooperative, connected and automated transport (CAT) and network and traffic management systems (NTM).

The metrics shown in the figure are:

- "Number of projects" (bars in pink).

- "Budget invested in the technology" (bars in light blue).

The technologies were analysed in the context of the projects within which they were researched. Within the 1946 projects, 33 SMO technologies were researched in 148 projects, 72 CAT technologies in 263 projects and 96 NTM technologies in 533 projects. Focusing on the top seven technologies identified, these represent $56 \%, 28 \%$ and $45 \%$ of the total technologies, respectively, for the SMO, CAT and NTM roadmaps. Table 1 provides these figures. 
Number of projects

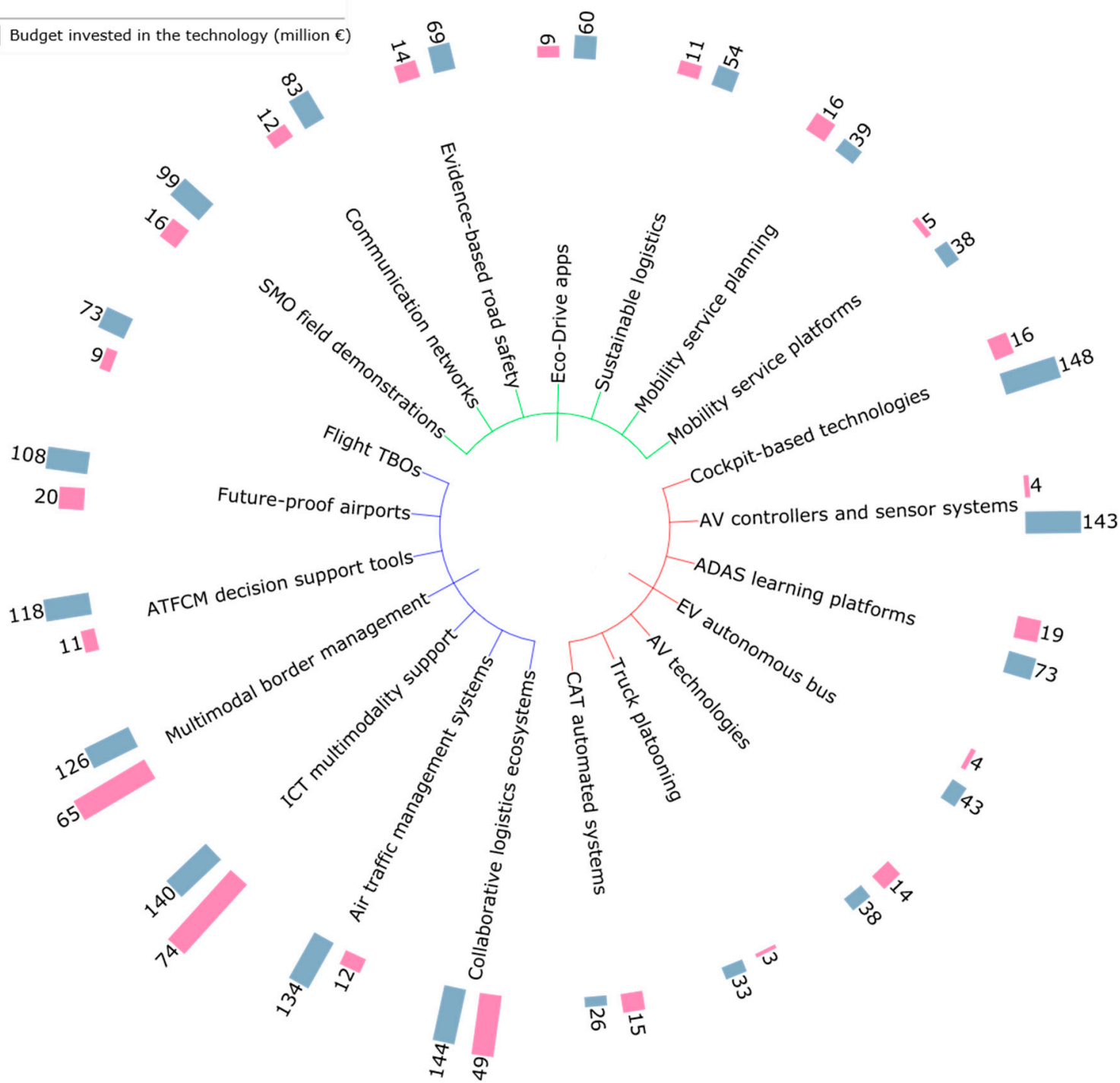

Figure 1. Top 7 technologies linked to the smart mobility and services (SMO), cooperative, connected and automated transport (CAT) and network and traffic management systems Strategic Transport Research and Innovation Agenda (STRIA) roadmaps. Transport Research and Innovation Monitoring and Information System (TRIMIS) data using the interactive tree of life [34]. Abbreviations-ADAS: advanced driver assistance systems; CAT: connected and automated transport; AV: autonomous vehicle; EV: electric vehicle; TBO: trajectory-based operation; ATFCM: air traffic flow and capacity management; ICT: information and communication technology. SMO-related technologies in green, CAT-related technologies in red and NTM-related technologies in blue.

Table 1. Number of technologies and projects assessed.

\begin{tabular}{cccc}
\hline Roadmap & $\begin{array}{c}\text { Number of } \\
\text { Technologies }\end{array}$ & $\begin{array}{c}\text { Number of } \\
\text { Projects }\end{array}$ & $\begin{array}{c}\text { Number of Projects Researching the } \\
\text { Top-7 Technologies (\%) }\end{array}$ \\
\hline SMO & 33 & 150 & $83(56 \%)$ \\
CAT & 72 & 265 & $75(28 \%)$ \\
NTM & 96 & 533 & $240(45 \%)$ \\
\hline
\end{tabular}


Regarding the geographical allocation of the beneficiaries of this research funding, i.e., the assessment of research in terms of funding received by MS, based on the beneficiaries' ("project partners") addresses:

- On SMO, Italy is the largest beneficiary in absolute terms, followed by Germany. Spain, the United Kingdom and France make up the top five [35].

- On CAT, Germany is by far is the largest beneficiary in absolute terms, followed by France. Italy, Spain and Sweden make the top five [36].

- On NTM, France is the largest beneficiary in absolute terms, closely followed by Germany. Italy, Spain and the United Kingdom make up the top five [37].

Some relevant information from the performed analyses are reported below for the top technologies in each roadmap.

Focusing on the CAT roadmap:

- Several cockpit-based technologies for improved pilot workflow have been researched in three high budget FP7 projects that ran between 2008 and 2013: ALICIA (All Condition Operations and Innovative Cockpit Infrastructure), SCARLETT (Scalable and Reconfigurable Electronics Platforms and Tools) and ACROSS (Advanced Cockpit for Reduction of Stress and Workload). These three projects account for about $80 \%$ of the budget invested in this technology (EUR $117 \mathrm{~m}$ out of EUR $148 \mathrm{~m}$ ). The developed technologies, pertinent mostly to air transport, focus on providing flight deck solutions for managing the peak workload situations that can occur during a flight, in order to reduce stress for pilots, and thus improve passenger safety.

- Four H2020 projects research controllers and sensor fusion systems, namely: L3Pilot (Piloting Automated Driving on European Roads), TrustVehicle (Improved trustworthiness and weather-independence of conditional automated vehicles in mixed traffic scenarios), NewControl (Integrated, Fail-Operational, Cognitive Perception, Planning and Control Systems for Highly Automated Vehicles) and PRYSTINE (Programmable Systems for Intelligence in Automobiles). All four projects are still on-going. The developed technologies, pertinent to road transport, focus on combining data delivered from different sources, and creating coherent and redundant information, and thus are fundamental for the future development of connected and automated driving solutions.

On the SMO roadmap:

- Three CIVITAS projects focus on SMO field demonstrations, namely MIMOSA (Making Innovation for Mobility Sustainable Actions) which ran from 2008 to 2013, DESTINATIONS and PORTIS (PORT-Cities: Integrating Sustainability), both of which started in 2016 and are still on-going. SMO field demonstrations demonstrate and evaluate integrated sets of sustainable mobility measures in cities and port-cities.

- Three H2020 projects funded under the INDUSTRIAL LEADERSHIP—Leadership in enabling and industrial technologies programme, namely 5G-MOBIX (5G for cooperative and connected automated mobility on X-border corridors), 5G-CARMEN (5G for Connected and Automated Road Mobility in the European Union) and 5G-DRIVE (5G Harmonised Research and trials for service evolution between EU and China) account for $60 \%$ of the budget for the research of communication networks for intelligent mobility. All three projects started in 2018 and are expected to finish at the end of 2021. The developed technologies focus on the widespread adoption of 5G-enabled urban and interurban corridors that will advance existing and future smart and connected mobility.

On the NTM roadmap:

- Collaborative logistic ecosystems are researched in 49 projects, seven of which have been funded under the H2020 Small and Medium Enterprise (SME) instrument. The FP7 ARCHIMEDES 
(Achieving Real Change with Innovative Transport Measures Demonstrating Energy Savings) project and the recently finished H2020 SELIS (Towards a Shared European Logistics Intelligent Information Space) and AEOLIX (Architecture for EurOpean Logistics Information eXchange) are the top three projects in terms of budget for this technology. The developed technologies focus on broad areas of logistics, targeting economic and environmental sustainability, while improving the overall competitiveness of goods transport in the supply chain.

- All projects that research air traffic management systems are H2020 projects. Ten out of 12 of them are SESAR (Single European Sky ATM Research Joint Undertaking) projects under the H2020 SESAR-2016-2 programme, part of the SESAR 2020 exploratory research and very large-scale demonstrations open call. The developed technologies aim to modernise and harmonise the European Air Traffic Management (ATM) System from an operational and technological perspective. A large part of the technology funding in NTM is allocated to aviation, something explained by the many projects under the SESAR joint undertaking. Even though this is something that can have a distorting effect in terms of presenting the results, nevertheless aviation technologies are included in the analysis since aviation is covered by the STRIA NTM roadmap.

In addition, the technology maturity was assessed for all technologies researched within the projects. The assessment is based on the technology readiness levels (TRLs), a method for estimating the maturity of technologies during the acquisition phase of a program, developed by the United States National Aeronautics and Space Administration (NASA) in the 1970s.

Table 2 provides the description for each of the nine TRLs, as taken from Annex G of the 2014-2015 H2020 Work Programme [38] and the corresponding development phases used in TRIMIS. As can be seen, in TRIMIS, the nine TRLs have been consolidated into four development phases: research/invention, validation, demonstration/prototyping/pilot production, and implementation. These are used to monitor and describe the maturing of each technology in a similar way to the original TRLs. The European Commission advised that EU-funded research and innovation projects should adopt the TRL scale in 2010; TRLs were then implemented for the EU H2020 framework programme [39], although in practice, TRLs are not consistently assigned to all H2020 projects. TRLs are based on a scale from 1 to 9 , with 9 being the most mature technology.

Table 2. TRL and corresponding TRIMIS development phases [40].

\begin{tabular}{crc}
\hline TRL & Description & TRIMIS Development Phase \\
\hline 1 & Basic principles observed & Research/Invention \\
2 & Technology concept formulated & \\
3 & Experimental proof of concept & Validation \\
4 & Technology validated in lab & \\
5 & Technology validated in relevant environment & Demonstration/Prototyping/Pilot \\
6 & Technology demonstrated in relevant environment & production \\
7 & System prototype demonstration in & \\
8 & operational environment & System complete and qualified \\
9 & Actual system proven in operational environment & Implementation \\
\hline
\end{tabular}

A development phase is assigned to each project-technology combination, by scanning the project for explicit references or based on expert judgement.

Identifying transport technologies researched at a low development phase aims at giving an early warning of potentially disruptive future technologies and helps in guiding the development of future research priorities and policy. On the other hand, identified technologies at a high development phase are a strong indication of technologies that are likely to have an impact on production products and operations in the short to medium term, and may contribute to products and systems that will be available in the shorter term. 
Figure 2 provides some initial results focusing on the top three technologies from Figure 1 (ranked in terms of allocated budget) for NTM (area in blue), CAT (area in red) and SMO (area in green) STRIA roadmaps. The y-axis in the figure shows the number of projects that research the specific technology.

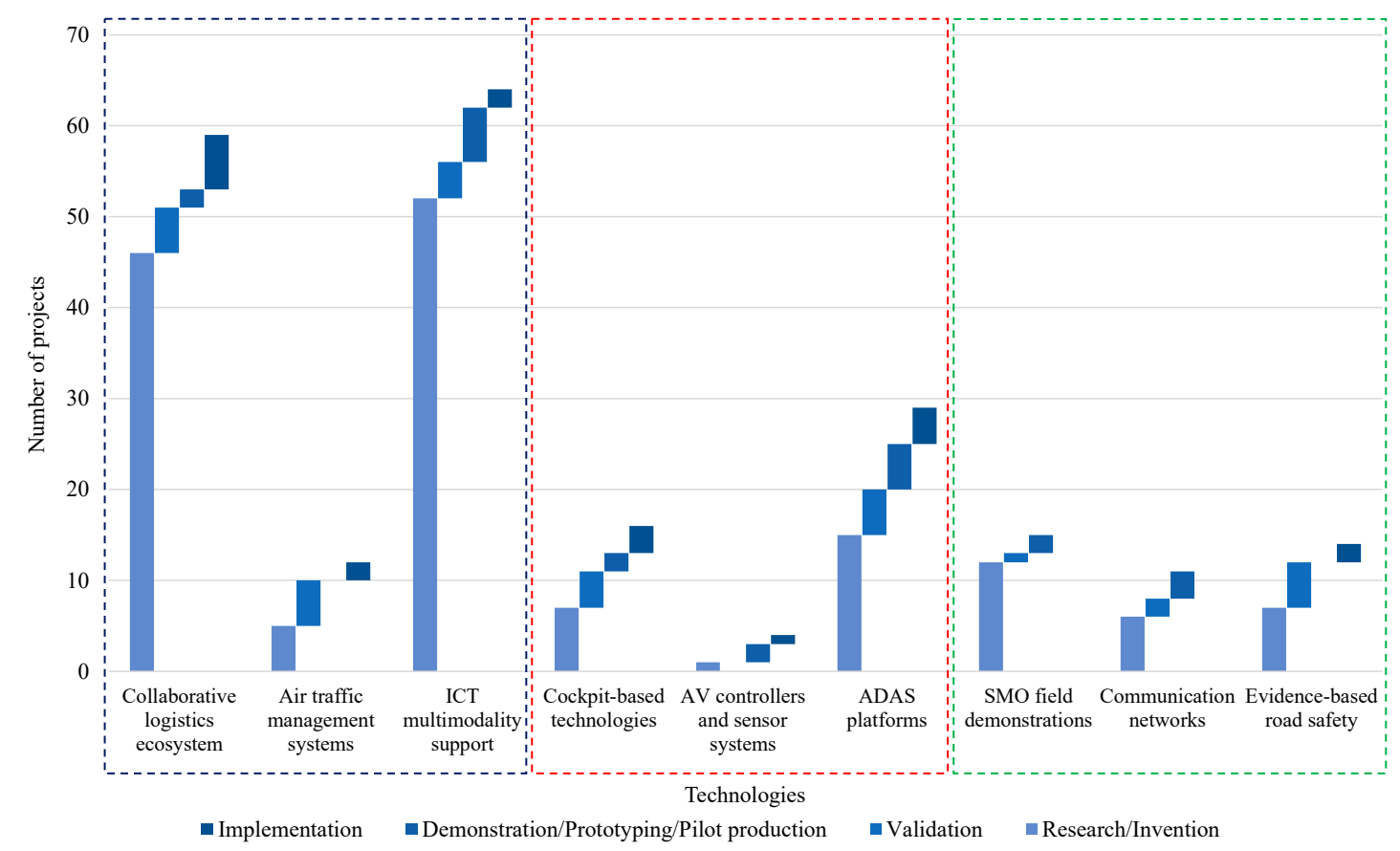

Figure 2. Number of projects and technology development phases for the top-3 technologies in terms of budget of the NTM, CAT and SMO STRIA roadmaps.

Even though the roadmap technology clusters are not comparable among them, the general observation is that most of the technologies have been researched in framework programmes at low development phase levels. This is more evident for two out of three dominant technologies within the NTM roadmap (i.e., collaborative logistics ecosystem and ICT multimodality support). On the contrary, the AV controllers and sensor systems category in the SMO roadmap, which has been researched only in four very large-scale projects, has reached a higher maturity.

\section{Conclusions}

The digital transformation of the transport sector is an ongoing process and TRIMIS provides a database of European transport-related R\&I projects and programmes and specific technology assessment methodologies that can be used as a basis for monitoring innovation capacities and supporting the assessment of the European transport sector performance and technological maturity status. This paper provides a first look at a comprehensive assessment of technologies relevant to the digital transformation by TRIMIS.

By linking technology metrics with organisational data, technology value chains can be identified and assessed. This information can contribute to the optimisation of funding allocation in European programmes and the development of targeted measures (i.e., policy initiatives) to promote transport innovation. Furthermore, analysing the development phase of technologies researched within framework programmes, it is possible to have an overview of technologies that are close to market introduction (for technologies with high maturity) or those, on the other hand, that need further development.

Regarding technologies that may have an impact on the digital transformation, a first analysis leads to the following conclusions: 
- There are several large-scale demonstration and implementation projects that focus on technologies researched, also in a more mature phase. This is the case of "Air traffic management" in the NTM (under the SESAR Joint Undertaking) and "AV controllers and sensors systems" in the CAT roadmap.

- A number of technologies are also addressed under the SME instrument scheme. This is especially evident within "Collaborative logistic ecosystems" in the NTM roadmap, and it is an indication that this theme attracts innovators who identify research and market gaps that need to be addressed, or who can come up with possible disruptive ideas that can further contribute to innovation.

The main technology themes identified above support the digital transformation of various elements of the transport sector, with a potential impact on the economy, the environment and quality of life. The identified technologies cover a broad spectrum of development phases, and include both more innovative technologies researched towards their market potential, and large-scale demonstration and validation of more mature technologies. It is expected that when more technologies become mature, demonstration and validation projects will be needed.

Even though at this stage, assessing the (cost) efficiency of the R\&I initiatives in terms of results against funding or number of projects is difficult, a first step has been made. This process will require-among others-additional indicators on the possible barriers, also beyond technology, and on the actual market uptake.

As a next step, in the future, these analyses will be provided with greater detail, and will include insights from other sources (i.e., IP activity, scientific research activity) in order to have an even more comprehensive overview of the technological developments in transport.

Author Contributions: Conceptualisation, A.T. and K.G.; methodology, A.T. and K.G.; software, K.G.; validation, K.G.; formal analysis, A.T. and K.G.; investigation, A.T. and K.G.; resources, F.P.; data curation, K.G.; writing-original draft preparation, A.T. and K.G.; writing-review and editing, F.P.; visualisation, K.G.; supervision, F.P.; project administration, F.P.; funding acquisition, F.P. All authors have read and agreed to the published version of the manuscript.

Funding: This research received no external funding.

Acknowledgments: The views expressed here are purely those of the authors and may not, under any circumstances, be regarded as an official position of the European Commission. The European Commission's Joint Research Centre (JRC) is in charge of the development of the Transport Research and Innovation Monitoring and Information System (TRIMIS), under the supervision of the European Commission's Directorate-General for Mobility and Transport (DG MOVE) and Directorate-General for Research and Innovation (DG RTD) which are co-leading the Strategic Transport Research and Innovation Agenda (STRIA). The authors would like to acknowledge the contribution in the data analysis of Gareth Horton of Ricardo-AEA Ltd. The paper was originally submitted to TRA2020.

Conflicts of Interest: The authors declare no conflict of interest.

$\begin{array}{ll}\text { Abbreviations } \\ \text { 5G } & \text { 5th Generation Mobile Communications Technology } \\ \text { ADAS } & \text { Advanced Driver Assistance Systems } \\ \text { AI } & \text { Artificial Intelligence } \\ \text { ATFCM } & \text { Air Traffic Flow and Capacity Management } \\ \text { ATM } & \text { Air Traffic Management } \\ \text { AV } & \text { Autonomous Vehicle } \\ \text { C-ITS } & \text { Cooperative Intelligent Transport Systems } \\ \text { CAT } & \text { Connected and Automated Transport } \\ \text { CEF } & \text { Connecting Europe Facility } \\ \text { CLIOS } & \text { Complex, Large-scale, Integrated, Open Systems } \\ \text { DG MOVE } & \text { Directorate-General for Mobility and Transport } \\ \text { DG RTD } & \text { Directorate-General for Research and Innovation } \\ \text { EU } & \text { European Union }\end{array}$




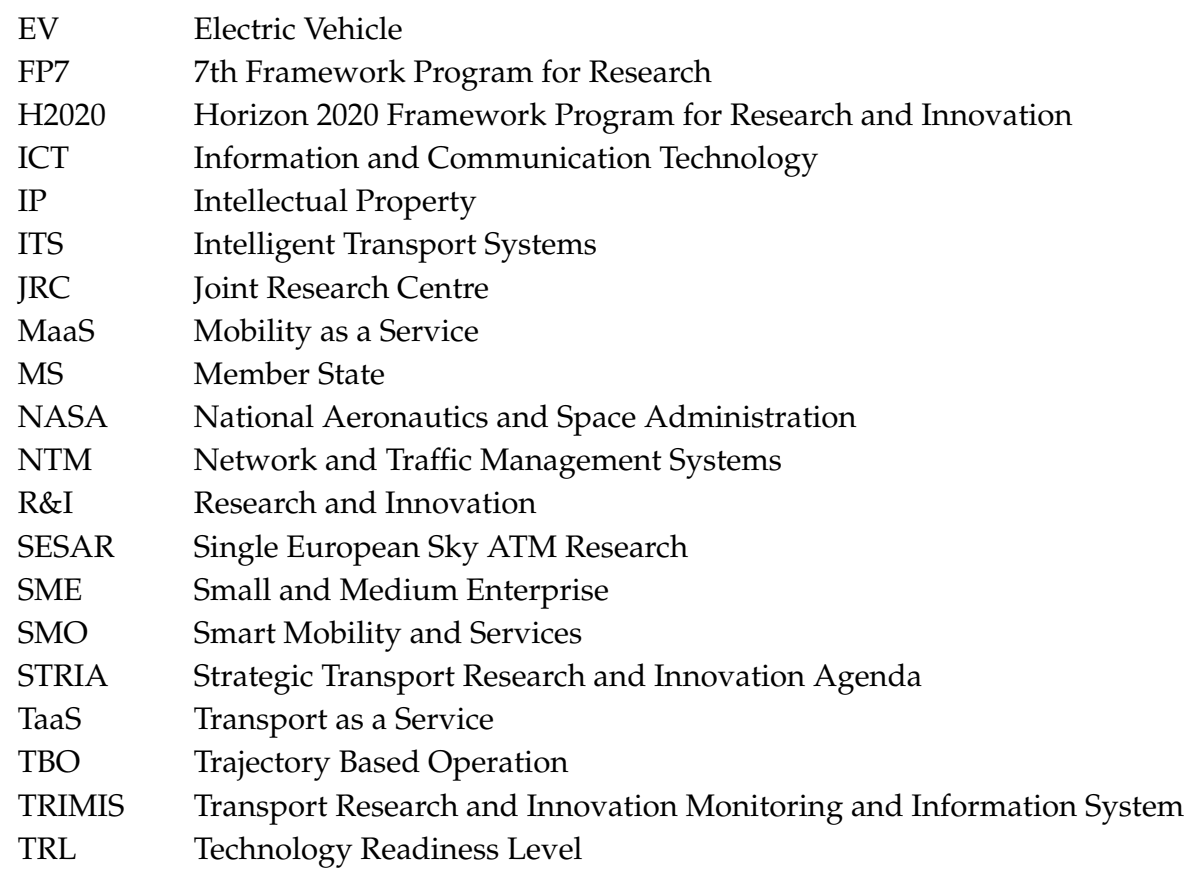

\section{References}

1. European Commission. The European Green Deal COM/2019/640 Final; European Commission: Brussels, Belgium, 2019.

2. Tsakalidis, A.; van Balen, M.; Gkoumas, K.; Pekar, F. Catalyzing Sustainable Transport Innovation through Policy Support and Monitoring: The Case of TRIMIS and the European Green Deal. Sustainability 2020, 12, 3171. [CrossRef]

3. Sussman, J.M.; Dodder, R.; McConnel, J.; Mostashari, A.; Sgouridis, S. The “CLIOS Process"-A User's Guide. Available online: http://web.mit.edu/hsr-group/documents/clios.pdf (accessed on 20 April 2020).

4. Weber, M.; Hoogma, R.; Lane, B.; Schot, J. Experimenting with Sustainable Transport Innovations: A Workbook for Strategic Niche Management; Universiteit Twente: Seville/Enschede, Spain, 1999; ISBN 978-90-365-1275-6.

5. Desruelle, P.; Baldini, G.; Barboni, M.; Bono, F.; Delipetrev, B.; Duch Brown, N.; Fernandez Macias, E.; Gkoumas, K.; Joossens, E.; Kalpaka, A.; et al. Digital Transformation in Transport, Construction, Energy, Government and Public Administration; Publications Office of the European Union: Luxembourg, 2019; ISBN 978-92-76-08613-0. [CrossRef]

6. Alonso Raposo, M.; Ciuffo, B.; Alves Dies, P.; Ardente, F.; Aurambout, J.-P.; Baldini, G.; Baranzelli, C.; Blagoeva, D.; Bobba, S.; Braun, R.; et al. The Future of Road Transport-Implications of Automated, Connected, Low-Carbon and Shared mobility; Publications Office of the European Union: Luxembourg, 2019; ISBN 978-92-76-14318-5. [CrossRef]

7. Vandecasteele, I.; Baranzelli, C.; Siragusa, A.; Aurambout, J.P.; Alberti, V.; Alonso Raposo, M.; Attardo, C.; Auteri, D.; Barranco, R.; Batista e Silva, F.; et al. The Future of Cities-Opportunities, Challenges and the Way Forward; Publications Office of the European Union: Luxembourg, 2019; ISBN 978-92-76-03847-4. [CrossRef]

8. Metz, D. Developing Policy for Urban Autonomous Vehicles: Impact on Congestion. Urban Sci. 2018, 2, 33. [CrossRef]

9. Holmberg, P.-E.; Collado, M.; Sarasini, S.; Williander, M. Mobility as a Service-MaaS: Describing the Framework. Available online: http://urn.kb.se/resolve?urn=urn:nbn:se:ri:diva-26060 (accessed on 20 April 2020).

10. Centobelli, P.; Cerchione, R.; Esposito, E. Shashi Evaluating environmental sustainability strategies in freight transport and logistics industry. Bus. Strateg. Environ. 2020, 29, 1563-1574. [CrossRef]

11. European Commission European Commission Adopts Rules on Operating Drones. Available online: https:// ec.europa.eu/transport/modes/air/news/2019-05-24-rules-operating-drones_en (accessed on 29 October 2019).

12. Aurambout, J.-P.; Gkoumas, K.; Ciuffo, B. Last mile delivery by drones: An estimation of viable market potential and access to citizens across European cities. Eur. Transp. Res. Rev. 2019, 11, 30. [CrossRef] 
13. European Commission. EUROPE ON THE MOVE-An Agenda for a Socially Fair Transition towards Clean, Competitive and Connected Mobility for all COM/2017/0283 Final; European Commission: Brussels, Belgium, 2017.

14. European Commission TRIMIS Transport and Research and Innovation Monitoring and Information System. Available online: https://rimis.ec.europa.eu/ (accessed on 29 October 2019).

15. Tsakalidis, A.; van Balen, M.; Gkoumas, K.; Grosso, M.; Haq, G.; Pekar, F. Towards an Integrated Monitoring and Assessment Framework for the Strategic Transport Research and Innovation Agenda-Using TRIMIS as a Policy Support Mechanism; Publications Office of the European Union: Luxembourg, 2018; ISBN 978-92-79-92583-2. [CrossRef]

16. Gkoumas, K.; Tsakalidis, A. A Framework for the Taxonomy and Assessment of New and Emerging Transport Technologies and Trends. Transport 2019, 34, 455-466. [CrossRef]

17. Gkoumas, K.; Tsakalidis, A.; van Balen, M.; Grosso, M.; Haq, G.; Ortega Hortelano, A.; Pekar, F. Inventory, Modelling and Assessment of New and Emerging Technologies and Trends (NETT) in the Transport Sector: A Methodology for the Transport Research and Innovation Monitoring and Information System (TRIMIS); Publications Office of the European Union: Luxembourg, 2018; ISBN 978-92-79-97224-9. [CrossRef]

18. European Commission. A European Strategy on Cooperative Intelligent Transport Systems, a Milestone towards Cooperative, Connected and Automated Mobility COM/2016/0766 Final; European Commission: Brussels, Belgium, 2016.

19. European Commission. EUROPE ON THE MOVE Sustainable Mobility for Europe: Safe, Connected, and Clean COM/2018/293 Final; European Commission: Brussels, Belgium, 2018.

20. European Commission. COMMISSION DELEGATED REGULATION (EU) ... /... Supplementing Directive 2010/40/EU of the European Parliament and of the Council with Regard to the Deployment and Operational Use of Cooperative Intelligent Transport Systems C/2019/1789 Final; European Commission: Brussels, Belgium, 2019.

21. Council of the European Union. COMMISSION DELEGATED REGULATION (EU) ... /... of 13.3.2019 Supplementing Directive 2010/40/EU of the European Parliament and of the Council with Regard to the Deployment and Operational Use of Cooperative Intelligent Transport Systems—Decision to Raise Objections to the Delegated Act; Council of the European Union: Brussels, Belgium, 2019; pp. 1-3.

22. Von Der Leyen, U. A Union that Strives for more My Agenda for Europe, POLITICAL GUIDELINES FOR THE NEXT EUROPEAN COMMISSION 2019-2024; European Commission: Brussels, Belgium, 2019.

23. European Commission A Europe Fit for the Digital Age. Available online: https://ec.europa.eu/info/priorities/ europe-fit-digital-age_en (accessed on 24 February 2020).

24. European Commission. Commission Work Programme 2020 A Union that Strives for more COM/2020/37 Final; European Commission: Brussels, Belgium, 2020.

25. van Balen, M.; Ortega Hortelano, A.; Grosso, M.; Tsakalidis, A.; Gkoumas, K.; Haq, G.; Pekar, F. EU Transport Research E Innovation Status Assessment Report: An Overview Based on the Transport Research and Innovation Monitoring and Information System (TRIMIS) Database; Publications Office of the European Union: Luxembourg, 2019; ISBN 978-92-76-09005-2. [CrossRef]

26. Glaser, B.G.; Strauss, A.L. The Discovery of Grounded Theory: Strategies for Qualitative Research; Aldine Transaction: New Brunswick, Canada, 1967; ISBN 978-0-20-230260-7.

27. Charmaz, K. Grounded Theory: Methodology and Theory Construction. In International Encyclopedia of the Social \& Behavioral Sciences; Smelser, N.J., Baltes, P.B., Eds.; Elsevier: Amsterdam, The Netherlands, 2001; pp. 6396-6399.

28. Strauss, A.; Corbin, J. Basics of Qualitative Research: Grounded Theory Procedures and Techniques; Sage: Newbury Park, CA, USA, 1990.

29. Tsakalidis, A.; Gkoumas, K.; van Balen, M.; Pekar, F. Investigating the technological impact of European transport research and innovation towards a clean and decarbonised urban landscape. In Proceedings of the 23rd Transport and Air Pollution Conference, Thessaloniki, Greece, 15-17 May 2019.

30. INTEND Home-Intend Project. Available online: https://intend-project.eu (accessed on 26 February 2019).

31. Tromaras, A.; Aggelakakis, A.; Bugarinović, M.; Pjevčević, D.; Moraglio, M. D2.1Transport Projects \& Future Technologies Synopses Handbook. Available online: https:/intend-project.eu/wp-content/uploads/2018/05/ intend-d-2.1-transport-projects-future-technologies-synopses-handbook.pdf (accessed on 20 April 2020).

32. European Commission. Towards Clean, Competitive and Connected Mobility: The Contribution of Transport Research and Innovation to the Mobility Package SWD/2017/0223 Final; European Commission: Brussels, Belgium, 2017. 
33. CPC Cooperative Patent Classification. Available online: https://www.cooperativepatentclassification.org (accessed on 26 February 2019).

34. Letunic, I.; Bork, P. Interactive Tree Of Life (iTOL) v4: Recent updates and new developments. Nucleic Acids Res. 2019, 47, W256-W259. [CrossRef] [PubMed]

35. Tsakalidis, A.; van Balen, M.; Gkoumas, K.; Haq, G.; Ortega Hortelano, A.; Grosso, M.; Pekár, F. Research and Innovation in Smart Mobility and Services in Europe: An Assessment Based on the Transport Research and Innovation Monitoring and Information System (TRIMIS); Publications Office of the European Union: Luxembourg, 2020; (Under publication).

36. Gkoumas, K.; van Balen, M.; Grosso, M.; Marques Dos Santos, F.L.; Tsakalidis, A.; Ortega Hortelano, A.; Haq, G.; Pekár, F. Research and Innovation in Connected and Automated Transport-An Assessment Based on the Transport Research and Innovation Monitoring and Information System (TRIMIS); Publications Office of the European Union: Luxembourg, 2019; ISBN 978-92-76-14121-1. [CrossRef]

37. Marques Dos Santos, F.; van Balen, M.; Gkoumas, K.; Grosso, M.; Ortega Hortelano, A.; Tsakalidis, A.; Haq, G.; Pekár, F. Research and Innovation in Network and Traffic Management Systems in Europe-An Assessment Based on the Transport Research and Innovation Monitoring and Information System (TRIMIS); Publications Office of the European Union: Luxembourg, 2020; (Under publication).

38. European Commission. Commission Decision C(2014)4995, Horizon 2020—Work Programme 2014-2015, Annex G: Technology Readiness Levels (TRL); European Commission: Brussels, Belgium, 2014.

39. Héder, M. From NASA to EU: The evolution of the TRL scale in Public Sector Innovation. Innov. J. 2017, 22, 3.

40. Gkoumas, K.; van Balen, M.; Ortega Hortelano, A.; Tsakalidis, A.; Grosso, M.; Haq, G.; Pekar, F. Research and Innovation in Transport Infrastructure in Europe: An Assessment Based on the Transport Research and Innovation Monitoring and Information System (TRIMIS); Publications Office of the European Union: Luxembourg, 2019; ISBN 978-92-76-09539-2. [CrossRef]

(C) 2020 by the authors. Licensee MDPI, Basel, Switzerland. This article is an open access article distributed under the terms and conditions of the Creative Commons Attribution (CC BY) license (http://creativecommons.org/licenses/by/4.0/). 